\title{
GOVERNANÇA AMBIENTAL EM CONSTRUÇÕES DE HIDRELÉTRICAS
}

\author{
Maria Clarice Alves Costa ${ }^{1}$ \\ Universidade Federal de Rondônia - UNIR \\ mariaclaricecosta@hotmail.com
}

Guilherme Giacon da Silva ${ }^{2}$

Universidade Federal de Rondônia - UNIR guilhermegiacon@hotmail.com

Dercio Bernardes de Souza $^{3}$

Universidade Federal de Rondônia - UNIR dercio@unir.br

Mariluce Paes de Souza ${ }^{4}$ Universidade Federal de Rondônia - UNIR mariluce@unir.br

\section{Resumo}

As hidrelétricas, que foi uma grande solução no passado para o desenvolvimento mundial, hoje é motivo de polêmicas em relação aos conflitos provocados nos diversos recursos do ecossistema global. O papel dos diferentes steakholders nem sempre é desempenhado como se espera de uma governança ambiental. Diante desse impasse é que se propôs este estudo com o objetivo de identificar quais os mecanismos de governança ambiental presentes nas construções de usinas hidrelétricas. Para a construção do artigo utilizou-se de análise sistemática de revisão, cuja busca utilizada para os artigos foi a base de dados Scopus, dos quais foram selecionados estudos relacionados a conflitos entre os recursos oriundos das construções de hidrelétricas em vários países. Dentre os diversos mecanismos da governança ambiental, observou-se em alguns países, como Brasil, Polônia, África e Indonésia, a existência de legislações na tentativa de solucionar tais impasses. No entanto, as ações não se constituem somente de normas, mas, também, verificou-se outros mecanismos como a participação de diversos atores internos e externos que direta ou indiretamente são afetados por esses tipos de projetos.

Palavras-chave: Usinas Hidrelétricas. Governança Ambiental.

\section{ENVIRONMENTAL GOVERNANCE IN HYDROELECTRIC DAMS}

\begin{abstract}
Hydroelectric dams, which were a great solution in the past for world development, are today the subject of controversy in relation to the conflicts caused about various resources of the global ecosystem. The role of the different stakeholders is not always performed as soon as expected from environmental governance. In view of this contradiction, the objective of this article is identifying which mechanisms of environmental governance are present in the construction of hydroelectric plants. For this construction, a systematic review analysis was used, whose the search used for the articles was from the Scopus database, in which studies were selected on the conflicts between the resources coming from the construction of hydroelectric plants in several countries. Among the various mechanisms of environmental governance, in some countries, such as Brazil, Poland, Africa and Indonesia, legislation has been observed in an attempt to solve a problem. This is not just a law, but other mechanisms such as the participation of the various internal and external actors affected by the hydroelectric construction project.
\end{abstract}

Keywords: Hydroelectric plants. Governance. Environmental.

\footnotetext{
${ }^{1}$ Técnico controle externo - Tribunal de Contas do Estado de Rondônia. Graduação em Administração pela Universidade de Passo Fundo

${ }^{2}$ Mestrando em Administração na Universidade Federal de Rondônia. Pós-Graduado em Licitações e Contratos pela UNIARASP e em Gestão Orçamentária do Setor Público pela Uniara-SP. Graduação em Ciências Econômicas pela Universidade Estadual Paulista Júlio de Mesquita Filho.

${ }^{3}$ Doutor em Agronegócios pelo Centro de Estudos e Pesquisas em Agronegócios CEPAN da Universidade Federal do Rio Grande do Sul UFRGS. Mestre em Administração pela Universidade Federal de Rondônia UNIR.

${ }^{4}$ Pós-Doutora em Administração pela Universidade Federal do Rio Grande do Sul (UFRGS) (2012), Doutora em Ciências Socioambientais pela Universidade Federal do Pará (UFPA)/Núcleo de Altos Estudos Amazônicos (NAEA) (2004). Mestre em Engenharia de Produção pela Universidade Federal de Santa Catarina (UFSC).
}

(c) (1) $\$$ Esta obra está licenciada sob uma licença 
INOVAÇÃO

\section{INTRODUÇÃO}

Os empreendimentos hidrelétricos são motivos de controvérsias quando se trata dos impactos ambientais e sociais causados quando das instalações de hidrelétricas. Um fator preponderante que muitas vezes se desconsidera é um planejamento aliado aos impactos socioambientais (CÂMARA, 2011). Tais impactos muitas vezes são detectados tardiamente quando o prejuízo é quase que irreversível, e o que se dá para fazer são medidas paliativas diante do dano causado (JUNG; RENK, 2019). Muitas vezes os interesses políticos estão à frente dos empreendimentos e por isso não se faz uma análise macro e de longo prazo, e com promessas de desenvolvimento e crescimento regional autorizam as licenças ambientais causando conflitos com a biodiversidade e a população ali instalada (OLIVEIRA; ZHOURI, 2005).

A solução das controvérsias é a universalização dos princípios da governança para que diversos atores atuem para se produzir resultados eficazes para problemas comuns (GONÇALVES, 2006; QUEIROZ; MOTTA-VEIGA, 2012). É necessário o fortalecimento da governança ambiental por meio de mecanismos institucionalizados e a sociedade civil apoiando nos princípios da transparência, participação, responsabilidade eficácia e coerência.

Alguns fatores merecem destaque quando do licenciamento ambiental: de um lado conhecimento imperfeito sobre o funcionamento dos ecossistemas, que contribui para que o tratamento do assunto não seja imperativo na questão; enquanto que no outro tentam "destravar o empreendimento"; não são elaborados para a avaliação dos impactos e a viabilidade dos projetos, mas para antecipar quais ações de compensação ou mitigação podem ser ajustadas para que os investimentos previstos não sejam bloqueados (PIAGENTINI; FAVARETO, 2014).

As etapas do processo de licenciamento ambiental, segundo Piagentini e Favareto (2014), são mundialmente semelhantes e envolvem a elaboração de estudo ambiental, a análise do órgão licenciador, a participação pública, a tomada de decisão e o acompanhamento da instalação e da operação, e, ainda, apresenta mesma estrutura e finalidade. No entanto, diferentes nações conduzem o processo de licenciamento ambiental com nuances, face às características de cada região, de cada ambiente político-institucional e conforme a importância dada às questões socioambientais pelos tomadores de decisão. Diante disso, este estudo tem como objetivo responder a seguinte pergunta: quais os mecanismos de governança ambiental presentes nas construções de usinas hidrelétricas? 
Justifica-se a pesquisa para identificar quais os mecanismos de governança ambiental que são utilizados pelos governantes para evitar conflitos gerados quando da construção das hidrelétricas e como são tratados. Este estudo é relevante socialmente porquanto vai demonstrar como os países lidam com os conflitos e quais os mecanismos de governança que são aplicados para a soluções das controvérsias. E por outro lado o artigo trará uma contribuição acadêmica pelo fato de enumerar, caso exista, os mecanismos de governança ambiental aplicados nos diversos países dos artigos selecionados e demonstrar quais as similaridades entre eles. Para isso o objetivo do estudo é identificar os mecanismos de governança ambiental presentes nas construções de usinas hidrelétricas, a partir de estudos preliminares de revisão sistemática sobre a temática.

\section{FUNDAMENTAÇÃO TEÓRICA}

A fundamentação teórica deste artigo é composta das definições e discussões sobre governança, governança ambiental e governança em empreendimentos hidrelétricos. Dessa forma, entende-se que as concepções fundamentais sobre o tema serão apresentadas para orientar as análises que seguem neste trabalho.

\subsection{GOVERNANÇA}

Governança é a "capacidade da sociedade determinar seu destino mediante um conjunto de condições (normas, acesso à informação e à participação, regras para a tomada de decisão) que permitem à coletividade (cidadãos e sociedade civil organizada) a gestão democrática dos rumos do Estado e da Sociedade" (FBOMS, 2007).

A construção de mecanismo de confiança mútua, com resolução de conflitos e solução de controvérsia, conduz a se caracterizar a governança como meio e processo em que é capaz de produzir resultados eficazes. A Comissão sobre Governança Global define o termo governança: " é a totalidade das diversas maneiras pelas quais os indivíduos e instituições públicas e privadas, administram seus problemas comuns; que não só diz respeito às instituições de regimes formais autorizados a impor obediência, mas também a acordos informais que atendam aos interesses das pessoas e instituições"; governança não é ação isolada em que esse busca espaços de participação e influência, mas uma ação conjunta de Estado e sociedade em busca de soluções e resultados para problemas comuns, (GONÇALVES, 2006).

A universalização dos princípios de governança em geral e de comportamento empresarial responsável conduziria o desaparecimento de políticas econômicas e sociais 
autônomas. Essas políticas estariam a cargo de uma constelação de stakeholders: setor público, setor privado, sindicatos, organizações não governamentais e organismos internacionais de vocação normativa ou reguladora, (SOUTELLO, 2001).

A Governança refere-se a sistemas de liderança, protocolos de controle gerencial, direitos de propriedade, direitos de decisão e outras práticas que dão às organizações autoridade e mandatos de ação, que foi distinguida de governança interna e mecanismos internos, por ser classificada em interna e mecanismos internos de governança corporativa. A distinção baseiase que determinado mecanismo de governança emana de dentro da empresa ou de fora dos limites da empresa (AGUILERA et al., 2015).

Os mecanismos de governança interna são: conselho de administração, propriedade e incentivos gerenciais. Esses três mecanismos internos compartilham a lógica de que quando efetivamente implementados, devem alinhar os interesses gerenciais e acionistas e resultar em maior desempenho financeiro global, enquanto que os mecanismos externos têm uma perspectiva holística que examina tanto o impacto direto sobre a governança corporativa eficaz e seu impacto indireto por meio de outros mecanismos de governança corporativa. Esses mecanismos, são aqueles que operam de fora do núcleo da empresa (AGUILERA, et al., 2015).

Aguilera, et al. (2015) define em seis os mecanismos de governança corporativa externa: sistema legal, controle corporativo, auditores externos, classificações de governança, stakeholder ativismo, e mídia; os mecanismos internos incluem um conselho estruturado efetivamente, contratos de remuneração que incentivam uma orientação dos acionistas e participações concentradas que levam ao monitoramento ativo dos executivos, que é ativado quando mecanismos internos para o controle o oportunismo gerencial falhou.

A governança assume vários conceitos de acordo com a sua aplicação; quando trata de métodos de gestão da empresa (governança corporativa); quanto aos meios de preservação ambiental (governança ambiental); gestão no combate ao suborno e à corrupção no âmbito da administração pública (governança pública) e a aplicação dos recursos da tecnologia da informação na gestão pública e política da administração pública (governança eletrônica ou egovernança: e-gov), (SOUTELLO, 2001), gestão em que diversos atores participam (governança participativa). Contudo este estudo tem como foco a governança ambiental.

\subsection{GOVERNANÇA AMBIENTAL}

A compreensão da relação homem/natureza, processos, dinâmicas, relações, estruturas e funcionamento está contemplado nas agendas de grupos de pesquisas, discursos políticos e 
adeptos ao tema ambiental e a sua preservação, contudo a importância do tema teve início em 1972 em Estocolmo quando da Conferência das Nações Unidas acerca do Meio Ambiente Humano, seguido em 1992, Rio de Janeiro, com a Conferência das Nações Unidas sobre o Meio Ambiente e o Desenvolvimento - CNUMAD -, ECO-92, e, em 2002, em Jonhanesburgo, a Conferência Mundial sobre Desenvolvimento Sustentável - Rio+10, (CÂMARA, 2011).

O debate acerca do tema ambiental ganhou espaço nos processos de construção das políticas públicas, por meio de modelos de desenvolvimento econômico, nas relações globais, quanto aos padrões de consumo e do comportamento das pessoas. Embora tenha um discurso mais presente acerca do tema ambiental, não há ainda uma importância robusta, o que dificulta a aplicação de ações concretas que a questão ambiental requer, e, dessa forma, o meio ambiente continua sendo degrado sem que haja uma resposta precisa para o fato (CÂMARA, 2011).

Diante da propagação do tema nos diversos canais apontou para os conceitos de governabilidade e governança ambiental, que instigaram para os debates em nível mundial e centrado nos diversos campos do estudo científico. O conceito de governabilidade e governança passaram a fazer parte do discurso mundial no final do século $\mathrm{XX}$, em que se buscou a compreensão das relações sociais, econômicas e ambientais nos diversos aspectos e espaços a que os termos estão inseridos (CÂMARA, 2011).

A governança ambiental é definida por Cavalcanti (2004) como “o arcabouço institucional de regras, instituições processos e comportamentos que afetam a maneira como os poderes são exercidos na esfera de políticas ou ações ligadas às relações da sociedade com o sistema ecológico”. A crise ecológica, na ótica de Câmara (2011), está em nível global (mudança climática), regional (embranquecimento dos corais no Caribe) ou local (chuvas ácidas em áreas industriais ou desertificação). Tais efeitos são consequências ou impactos de pressões antrópicas no meio natural, motivados pelo crescimento econômico, população e mudança nos padrões de consumo, dentre outros, como se visualiza na Figura 1: 
INOVAÇÃO

Figura 1. Crise ecológica

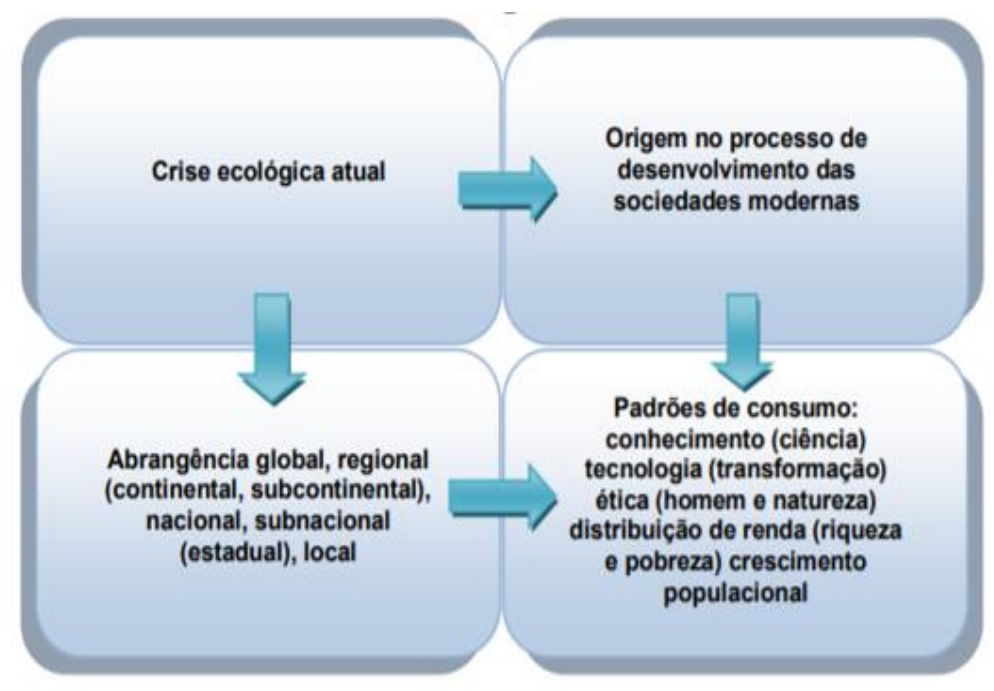

Fonte: Câmara, 2011.

O uso, a ocupação do solo e a apropriação dos recursos naturais está sofrendo por alterações de intensidades e abrangências distintas em dimensão global, que compromete o desenvolvimento de forma sustentável comprometendo a população e gerações futuras, (CÂMARA, 2011). Com esse cenário, os gestores públicos encontram barreiras para o alcance da eficácia administrativa, quando se trata de políticas públicas para a redução dos níveis de pobreza e a exclusão social. Dessa forma é necessário fazer uma análise da estrutura da governança, as habilidades e o processo de aprendizagem para que se possa desenhar as organizações (CÂMARA, 2011).

A questão ambiental, recente objeto de políticas públicas, requer atenção crescente dos governos. A Conferência Rio+20, realizada em 2012, no Rio de Janeiro, renovou o compromisso internacional pelo desenvolvimento sustentável, como tema central a governança ambiental e a estrutura político-institucional para o desenvolvimento sustentável (MOURA, 2013). A governança ambiental envolve todos, e individualmente cada um, nas decisões acerca do meio ambiente, a fim de que a adesão seja incondicional ao projeto para que se mantenha a integridade do planeta. Refere-se, também, a governança ambiental ao conjunto de iniciativas, regras, instâncias e processos que permitam que a sociedade, por meio de associações, organizações civis, possam exercer o controle social (JACOBI; SINISGALLI, 2012).

O Word Resources Institute - WRI (2009) relaciona algumas capacidades e ferramentas para o processo de governança ambiental para o setor público: 1) estabelecer e aplicar leis que 
determinem quem tem o direito de usar o meio ambiente e quem deve protege-lo; 2) promover a gestão dos recursos naturais, incluindo áreas protegidas, bens comuns ou públicos (como os mares, rios de um país); 3) restringir o comportamento de indivíduos e corporações que ameacem o meio ambiente; 4) definir e aplicar regras ao mercado e aos agentes privados; 5) designar fundos e instituições públicas para a preservação ou o desenvolvimento e 6) promover $\mathrm{o}$ acesso equitativo aos recursos naturais.

A governança promotora do desenvolvimento sustentável deve ser entendida como uma ferramenta que insere a sustentabilidade no âmbito das políticas públicas e suas inter-relações, isso, em razão de que se entender a sustentabilidade segmentada prejudica a implementação de ações e instrumentos da política ambiental e demais políticas públicas. Assim a governança tem o papel de aumentar a capacidade de processar as demandas e articulá-las com os processos públicos e privados de tomadas de decisão, em busca do equilíbrio entre os mecanismos burocráticos e a participação dos diversos setores da sociedade civil interessados na sustentabilidade do desenvolvimento (MOURA; BEZERRA, 2014); com ações preventivas e repressivas, com o objetivo de preservação ambiental a todos (DA COSTA et al., 2021).

Nesse sentido, ações para se definir responsabilidades e diretrizes para a avaliação de impacto ambiental e a salvaguarda dos recursos naturais deve ser feito por meio de planejamento racional, como instrumento para a obtenção de resultados em benefício das gerações atuais e futuras, segundo o Ministério do Meio Ambiente-MMA. O desafio é construir uma política que integre o setor produtivo e o meio ambiente promovendo a adequação do país às exigências do comércio interno e externo (BRASIL, [2020]). O MMA por meio dos órgãos colegiados e entidades vinculadas à política ambiental constituem mecanismos de gestão para subsidiar políticas, planos, programas e projetos de contabilidade e valoração econômica dos recursos naturais, remuneração dos serviços ambientais, promoção da inovação do setor produtivo e estímulo ao consumo sustentável (BRASIL, [2020]).

Conflitos e assimetrias de poder estão com frequência nos mecanismos e com certa relevância quando se trata de assuntos ambientais no Brasil, como nos conselhos de meio ambiente em níveis federal, estadual e municipal, nos relatórios de impacto ambiental as audiências públicas e nos comitês de bacias hidrográficas, situações em que há prevalência de assimetrias de poder e informação (CÂMARA, 2011). O processo de governança envolve tomadores e não tomadores de decisão com objetivo comum, seja um problema a ser enfrentado, ou a gestão, em que a participação descentralizada esteja inserida no processo. Dessa forma, há uma interação dos tomadores de decisões, por meio de atuação integrada e o ganho para os partícipes (CÂMARA, 2011). 
Superar padrões de comportamento oportunista por padrões de comportamento responsável; a adoção de códigos consensuais de cidadania empresarial e de mecanismos confiáveis de verificação; desenvolvimento de métodos de gestão capazes de conciliar os anseios diversos da sociedade civil; manter um equilíbrio entre iniciativa privada e os imperativos da cidadania empresarial são fatores de evolução da governança (SOUTELLO, 2001).

Criar e aprimorar condições de governança ambiental é um desafio local e global, mesmo com a participação de regimes multilaterais, instrumento de controles e econômicos; o relatório de Recursos Mundiais 2002-2004 - Decisões pela Terra - Equilíbrio, Voz e Poder elenca elementos de governança ambiental: 1) instituições e leis; 2) direitos de participação e representação; 3) nível de autoridade; 4) responsabilização e transparência; 5) direitos de propriedade e posse; 6) mercados e fluxos financeiros e 7) ciência e risco (GOMIDES; SILVA, 2010). A governança ambiental deve ter em vista o desenvolvimento sustentável e equitativo e deve-se apoiar nos princípios: da transparência, participação, responsabilidade, eficácia e coerência; implica também processos de decisões claros, diálogos abertos com os intervenientes sociais e econômicos e outras organizações da sociedade civil, medidas de combate a corrupção, promoção da segurança do Estado e das pessoas e colaboração entres os setores públicos e privados (GOMIDES et al., 2010).

Para fortalecer a governança ambiental pode-se valer de muitos mecanismos institucionalizados ou não, como as arenas de negociação, as práticas educativas e a participação da sociedade civil, que são ferramentas que contribuem para o processo de construção de tomada de decisão compartilhada (CÂMARA, 2011). Quanto às questões ambientais, os mecanismos para a democracia deliberativa têm avançado; embora há pouca presença dos grupos sociais comumente excluídos dos mecanismos tradicionais de deliberação como atores que têm presença nos processos decisórios, que reflete nos múltiplos conflitos socioambientais, principalmente os voltados à construção de usinas hidroelétricas e obras infra estruturais que afetam a vida da sociedade (CÂMARA, 2011).

Câmara (2011) entende que existe o desafio de compartilhar para a sociedade em geral a necessidade de se conhecer e se mobilizar para a redução dos impactos das mudanças climáticas, que tanto afetam as condições de vida, a qualidade ambiental, como ações que mobilizem para a redução das desigualdades e melhoria das condições e práticas pautadas nos princípios e diretrizes de sociedades sustentáveis. 


\section{ARTIGO}

INOVAÇÃo

\subsection{GOVERNANÇA EM EMPREENDIMENTOS HIDRELÉTRICOS}

Associa-se aos grandes empreendimentos hidrelétricos significativos impactos ambientais, sociais e à saúde, com a viabilidade atrelada as licenças ambientais, na ótica de Queiroz et. al. (2012). Para esse autor, os conflitos inerentes a esses projetos estão associados à inundação de áreas povoadas para a formação do reservatório, que provoca o deslocamento compulsório e a ruptura social, mudança no bioma com interferência na cadeia alimentar, bem como a alteração no processo produtivo que sustenta a base do agro extrativista e na caça. Acontece que os impactos não são considerados no momento do planejamento. Os estudos de impactos ambientais não contemplam os impactos socioambientais, o que obriga a posteriori ações para mitigar e compensar as perdas, que não um padrão de gestão sustentável para empreendimentos como os de hidrelétricos (QUEIROZ et al., 2012).

Assim, os megaprojetos de infraestrutura ameaçam o meio ambiente e violam direitos humanos, isso se dá em razão dos modelos produtivos, pós globalização, que fomenta a exploração intensiva dos recursos naturais, assim como a natureza, o homem em seu habitat e a cultura por meio da apropriação e expropriação (JUNG; RENK, 2019). A exploração dos recursos renováveis e não renováveis surgem os conflitos socioambientais nas diversas concepções: território, natureza e ambiente que ameaçam a própria democracia, vez que os grandes empreendimentos são construídos sem o aval da população atingida, que traz gravames sociais. Essas permissões ocorrem pelo fato de que os sujeitos alijados dos seus direitos estão distantes do padrão de desenvolvimento promovido e da lógica universalista (JUNG et al., 2019).

O Jogo político é presente na adequação ambiental, em busca de viabilizar o projeto técnico, inserindo "externalidades ambientais" e sociais como as medidas mitigatórias e compensatórias desde que não inviabilizem o projeto no ponto de vista econômicoorçamentário; assim há a dominação do espaço para a tomada de decisões numa visão hegemônica das possibilidades de "uso" dos recursos naturais na ótica de mercado (ZHOURI, 2008).

O estudo de Queiroz et al. (2012) menciona que o custo social dos empreendimentos hidrelétricos está diretamente ligado aos indicadores sociais da região, no caso do Brasil, em razão dos índices de pobreza no status quo da educação, saúde, saneamento, habitação e trabalho no ambiente afetado pelas construções. Outro agravante é o processo de desapropriação e relocação que atinge de forma direta as atividades desenvolvidas pelos habitantes ribeirinhos, como a agricultura, caça, pesca e extração vegetal. Embora, haja 
propostas de ações para compensar as perdas da população atingida pela construção de hidrelétricas são inadequadas e insuficientes, em muitos casos em razão de corrupção e efetividade das ações prometidas (QUEIROZ et al., 2012).

Os processos de licenciamento ambiental para construção de hidrelétricas são os que impulsionam a injustiça ambiental, bem como a desigualdade na distribuição ecológica, quando se nega as condições sociais aos atingidos pelas barragens. Assim, os estudos do impacto ambiental tendem a desqualificar o ambiente em que serão projetadas as barragens, fato que reforça a reificação e invisibilidade das comunidades (OLIVEIRA; ZHOURI, 2005).

Aponta, Queiroz et al. (2012) os impactos sociais da Usina Hidrelétrica Tucuruí, no Brasil: "isolamento da população ribeirinha no enchimento do reservatório; compensação financeira para o s municípios que tiveram áreas inundadas por meio de Lei dos Royalties, excluindo a jusante; migração interna, especialmente da população a jusante; ocupação irregular e desordenada; conflitos de uso; ausência de infraestrutura; praga de mosquitos; riscos de manifestações de doenças de veiculação hídrica; alteração da qualidade da água; perda do sustento e renda; alagamento de vicinais no período de chuva; cadeia alimentar contaminada por metil-mercúrio e dificuldades de deslocamento e acesso a outras áreas e serviços”.

Os impactos econômicos, também, foram destaque no estudo de Queiroz et al. (2012) como: "geração de empregos; perda na produção pesqueira; mudança na estrutura produtiva agroextrativista; declínio da produção tradicional e estagnação econômica, sobretudo, a jusante que teve queda da produtividade na extração do cacau nativo e do açaí das margens do rio por causa das alterações na qualidade da água; urbanização desordenada; pesca comercial no reservatório; conflito entre pescador artesanal e comercial; queda de produção nas atividades tradicionais desenvolvidas nas várzeas apontadas pelos produtores locais; conflitos de interesse em decorrência da valorização da terra; expansão da exploração predatória da madeira e conflito fundiário" (QUEIROZ et al., 2012).

A gestão participativa e conduta ética foram imparciais em todos os atores envolvidos no processo de avaliação e viabilidade do projeto de hidrelétrica na conclusão do estudo de Queiroz et al. (2012). Desenvolvimento de metodologias de gestão participativa para a avaliação de impactos sociais com transparência, monitoramento que identifiquem a eficiência das ações, que contribuam com a avaliação ambiental estratégica de maneira que mitiguem os impactos sociais e à saúde, atrelados ao desenvolvimento regional (QUEIROZ et al., 2012). 


\section{ARTIGO}

INOVAÇÃO

\section{METODOLOGIA}

$\mathrm{O}$ artigo é de natureza qualitativa, com três momentos: planejamento, execução e discussão. As etapas estão organizadas por seleção compilada de artigos relacionados ao tema governança, cuja base de dados Scopus da Elsevier, que é um banco de dados, com revisão dos pares, conta com ferramenta inteligente para acompanhar, analisar e apoia à pesquisa Bibliometria (SCOPUS, 2019), dentre os quais foram divididos em 4 grupos de pesquisadores. Após, foi realizada a leitura preliminar dos resumos para identificar afinidade com o conceito de governança. No segundo momento, definiu-se o objetivo do estudo que é identificar os mecanismos de governança ambiental presentes nas construções de usinas hidrelétricas, por meio de análise sistemática de revisão sobre a temática: quais os mecanismos de governança ambiental presentes nas construções de usinas hidrelétricas?

$\mathrm{Na}$ fase do planejamento, após a identificação da lacuna preexistente quanto ao tema do estudo e necessidade de realização de uma pesquisa para verificar a existência da governança em hidrelétricas. Em seguida determinou-se os termos de busca, que foi em língua inglesa pela amplitude da base de dados disponíveis de artigos com as palavras: river, water, biodiversidy, ecosystem servisse, lake, fish, construction, national, techonology follow-up, monitoring, land use change, biota, Science, animal, operation. Depois fez-se novo filtro com o termo: hydropower, que obteve 456 resultados de artigos. Desses 456 artigos foram divididos em quatro grupos de pesquisadores, sendo que cada grupo ficou com 113 artigos, dos quais, foram feitas as leituras dos resumos e palavras chaves: peixe, animal, sociedade, ribeirinhos, ecossistemas, devastação, temperatura e meio ambiente e que por meio dessa leitura foi possível encontrar conflitos em razão da falta da governança nas construções de hidrelétricas.

Na execução da pesquisa, após a leitura dos resumos e palavras chaves dos 113 artigos, foram excluídos 58 artigos por não estarem correlatos aos objetivos de pesquisa. Restaram para estudo 55 artigos; desse total buscou-se os artigos com acesso público, obteve-se o acesso livre em 50 artigos, desses 18 foram excluídos em razão de não serem pertinentes ao objetivo de pesquisa. Assim, restaram 32 artigos, para desenvolvimento da pesquisa. Todo o processo para obtenção de artigos pertinentes ao tema foi por meio do PRISMA (Preferred Reporting Items for Systematic Reviews and Meta-Analyses), por ser uma ferramenta que orienta a confecção de artigos científicos por meio de análise sistemática de revisão, como se verifica na figura 2. 


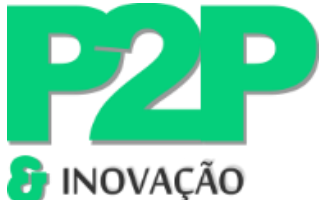

ARTIGO

Figura 2: Fluxograma dos artigos.

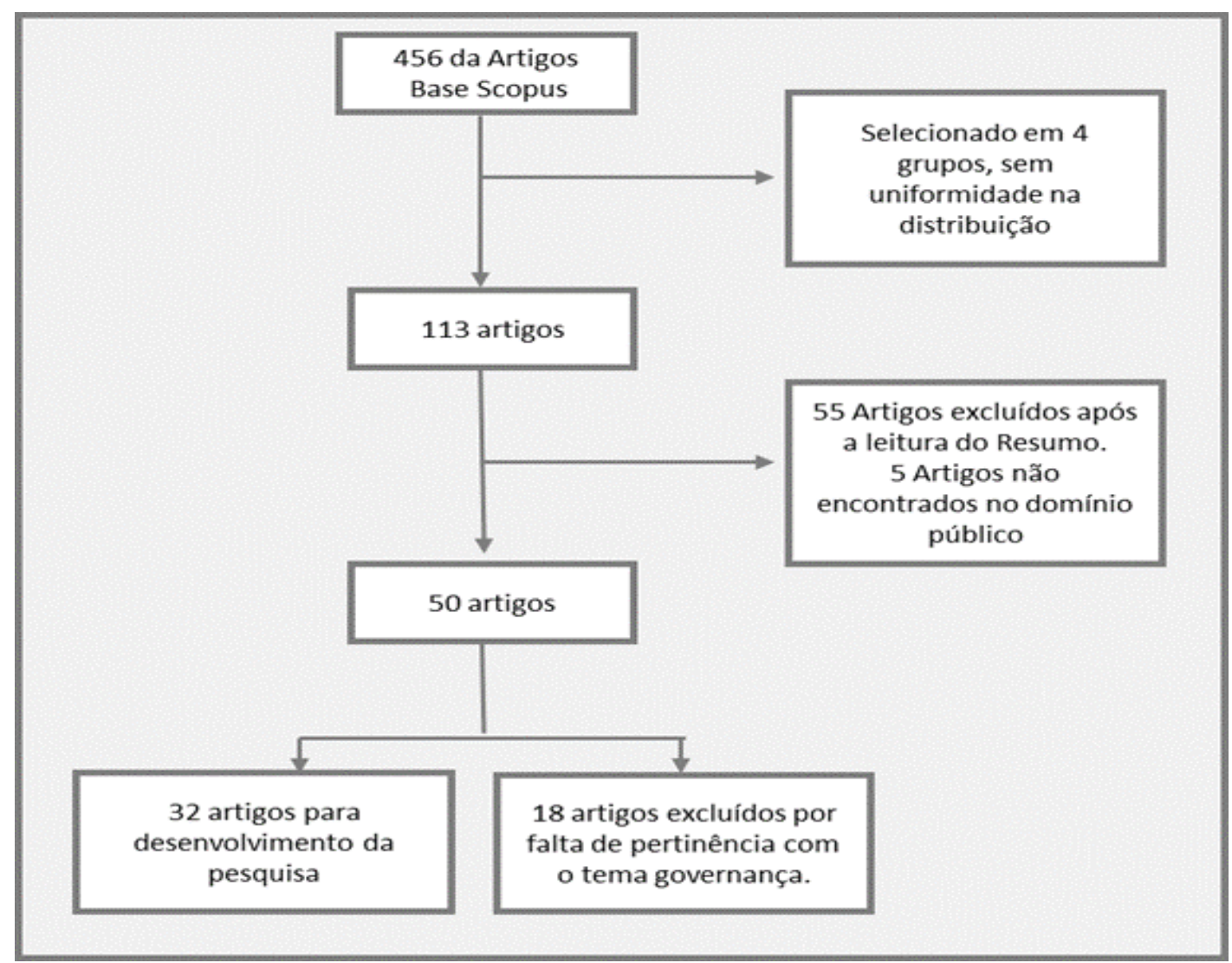

Fonte: Adaptado de Zhou et. al., 2016.

\section{RESULTADOS E DISCUSSÃO}

Do total dos artigos classificados verificou-se que a quantidade de autores foi variável, desde um autor até de 12 autores, sendo que o de menor participante é brasileiro e trata-se do estudo de impactos ambientais referente a carnívoros, a metodologia utilizada foi revisão bibliométrica, publicado no ano de 2017, publicado numa revista estrangeira e citado uma vez.

Dos nossos estudos verificou-se que muitos recursos alojados nas áreas de construção de hidrelétricas sofrem ameaças de extinção ou são obrigados a se deslocarem para outros ambientes sem nenhum planejamento antecipado pelos agentes responsáveis pela concessão da construção e/ou pela responsável pelo projeto da hidrelétrica. Os países, cujos artigos classificados que atenderam aos critérios foram: África, Brasil, Canadá, China, Colômbia, Coréia do Sul, Egito, Estados Unidos, Indonésia, Itália, México, Polônia, Suécia, Suíça, Sudão e Vietnã.

No caso do Brasil os conflitos estão relacionados a água, degradação ambiental, poluição, pesca ilegal, população circunvizinhas à construção, população indígena, extinção de 
animais (tartarugas, roedores, carnívoros, formigas, predadores), vegetação, rios; e as causas relacionadas foram as barragens rodoviárias que são construídas quando do empreendimento, as hidrelétricas, a exploração de minérios e petróleo. O conflito humano se dá por duas razões, uns são retirados do seu ambiente para as construções tirando o sustento e atividade dos pescadores, e outros são instalados para a construção, esses são ameaças para os carnívoros e tartarugas e seus ovos, pois servem de alimento. Outro tipo de conflito, o ambiental, foram os incêndios provocados pelo homem para a remoção de madeira, alagamentos comprometendo a biodiversidade, fato verificado nos estudos no Brasil. O desmatamento na Amazônia causou a diminuição de espécies raras como dos roedores, embora o estudo tenha catalogado duas novas espécies de roedores.

No Brasil houve um afrouxamento da legislação em favor do setor industrial das hidrelétricas. Não foi feito estudos preliminares para a implantação das usinas hidrelétricas e restou pendente normas para regulamentar a compensação da biodiversidade e o ambiente nessas áreas afetadas pela construção. Enquanto, que na Colômbia os recursos em conflito foram as vegetações nativas e os répteis por conta construção das hidrelétricas, exploração de minérios e petróleo, agricultura, pecuária e, humana. O povo daquele país tem uma crença cultural e por isso grande parte do extermínio dos répteis é em razão do entendimento de que tais animais são perigosos e desagradáveis.

Na África o estudo das plantas (Inversodicraea e Podostemaceae tiveram 63\% dessas plantas exterminadas e as demais estão ameaçadas), rio, água, vegetação, terra e população são os recursos em conflitos em razão da construção de hidrelétricas no país. Na construção de hidrelétricas financiadas pela China restou evidenciado que não houve a preocupação nos projetos com a biodiversidade o que colocou em risco a reprodução dos peixes; acesso a água em razão de represamento para produção agrícola; e, conflito transfronteiriço entre países. No caso da população o conflito foi que a população não foi assistida quando foram desalojadas do espaço em que viviam, ficaram à mercê da situação, sem os alojamentos, que foi tratado nos artigos a necessidade de leis para resguardar a população da ingerência da China na exploração dos recursos naquele país.

Na Indonésia o conflito listado foi animal (pangolim), em razão da devastação, construção de rodovias, deslizamento de terra, por conta da construção de hidrelétricas; além da questão da urbanização que fomentou o consumo desse animal e o estímulo ao comércio devido ao valor no mercado, que acelerou a extinção da espécie naquele país, mesmo como leis que proibissem o comércio do animal. Não houve ação do governo para coibir ou limitar as 
construções de hidrelétricas nos locais em que habitavam os pingolins o que causou o extermínio de grande parte da desse animal.

Os recursos ameaçados na China são: peixes, rio, água, população, plantio-sementes (quando da inundação, a água lava a terra e leva parte da semente semeada, que prejudica a colheita), ecologia dos rios, alteração do clima e temperatura causados pela construção de hidrelétrica. A construção das hidrelétricas 3S na China é um conflito de magnitude social, ambiental e econômico por terem sido construídas em cascatas podem acarretar sobrecarga nas últimas hidrelétrica ou a subutilização dessas construções quando ocorrer escassez de água, que pode interferir na qualidade de peixes para consumo; o que pode observar que não houve um estudo detalhado das consequências para esse tipo de construção.

Os sedimentos alteraram o ambiente dos peixes nas construções das hidrelétricas na China que acarretaram a diminuição de certos peixes e espécies de peixes, enquanto, que, em outros aumentaram em razão do depósito de areia e lama. Verificou-se também naquele país a degradação ambiental, que é desencadeada pela combinação de crescimento populacional e fontes renováveis de recursos, em razão das bacias hidrográficas transfronteiriças. Outros fatores que provocaram conflitos foram a mineração de areia, a infraestruturas de água e dique, a mudança climática, salinização das terras cultiváveis, erosão acelerada da costa, extensão dos manguezais pântanos.

No Canadá os recursos listados em conflitos são os peixes, vegetações e água, em razão das hidrelétricas e mineração. Nos Estados Unidos os conflitos são causados pela água, peixe, algas. Enquanto, que no México o conflito se dá em razão dos recursos da água em detritos de irrigação e eletricidade por conta de construção de hidrelétrica por interesses de mineração de propriedade dos Estados Unidos. No Camboja e Vietnã o recurso em conflito é água, plantações, vegetação em razão da vazão de água oriundas das hidrelétricas. As plantações podem ser prejudicadas em razão do excesso ou falta de água. Deve-se ter um planejamento/controle para que as inundações não afetem a produção na região. Enquanto, no Sudão e Egito o conflito se deu em razão da degradação e esgotamento e utilização equitativa da água e crescimento populacional, falta de atuação de políticas públicas efetivas, devastação ambiental e social.

Polônia o conflito é em razão de construção de pequenas hidrelétricas em áreas de proteção, o que deve apresentar a avaliação do impacto ambiental, que pode limitar a construção. Na Coréia do Sul o conflito está entre os recursos: água, clima, temperatura, poluição e ecossistema e o setor energético por meio da construção de hidrelétricas. 


\section{ARTIGO}

INOVAÇÃO

O aumento global da temperatura foi abordado nos estudos como conflito ambiental na Suécia em razão do degelo e pelo aquecimento inibir a formação de geleiras que compromete a manutenção dos reservatórios. Enquanto, que na Suíça o conflito foi verificado na qualidade da água em virtude do nível dos reservatórios que trouxeram alterações físico/químico da água o que afeta todo o ecossistema. E por fim, na Itália notou-se o conflito gerado pelas hidrelétricas pela sobrecarga de sedimentos a jusante no rio Scalcoggia.

Os empreendimentos hidrelétricos carecem de planejamentos que minimizem os conflitos entre os recursos que causam consequências irreparáveis no ecossistema, fato demonstrado nos artigos selecionados neste estudo. Como exemplo, cita-se a construção de hidrelétrica na Bacia do Rio Nilo que apesar de oportunidades criadas, também causou incerteza a outros países ribeirinhos e as hidrelétricas nos rios Sekong, Sesan e Srepok na China que por falta de planejamento correto os efeitos negativos poderão ser cumulativos. Neste sentido Queiroz et al. (2012) afirma que os impactos não são considerados no momento do planejamento, bem como os estudos não contemplam os impactos socioambientais, e que no futuro é necessário ações para mitigar as perdas.

Os projetos hidrelétricos em países como o Brasil, África, China, Sudão e Vietnã os conflitos entre a população diretamente impactadas com a presença de construção de grande porte, em razão de retiradas do seu habitat sem projeto de inserção, como o caso dos indígenas no Amazônia que tiveram que lutar para demonstrar os crimes cometidos pelos projetos naquela região. Outro fato relevante é o caso das barragens de Gibe e dos sistemas de irrigação Lebre da Etiópica que fica clara a ausência de programa para que a população tenha acesso à terra e oportunidades econômicas em outros assentamentos. Jung e Renk (2019) ponderam que os megaprojetos de infraestrutura ameaçam o meio ambiente e violam direitos humanos, fomenta a exploração intensiva dos recursos naturais e do homem em seu habitat e a cultura por meio da apropriação e expropriação.

Para os cidadãos americanos as hidrelétricas são recursos indispensáveis, uma realidade e crescente necessidade humana, contudo no estudo verificam-se falhas no planejamento dos projetos, pelo fato de que após cobrir os custos operacionais, as receitas do Projeto de Armazenamento do Rio Colorado são distribuídas ao Fundo da Bacia do Alto Colorado, na região do Glen Canyon Dam para projetos de irrigação, programas ambientais, em busca de medidas para a recuperação de peixes, controle de salinidade, ações de gerenciamento de reservatório, para introdução de peixes; ações após construção do projeto. Esses fatos compravam que não houve governança, pois, governança não é ação isolada, mas uma ação 
conjunta de Estado e sociedade em busca de soluções e resultados para problemas comuns (GONÇALVES, 2006).

A presença de sugestões de ações mitigatórias por conta dos diversos recursos em risco leva-nos ao raciocínio de que não se estabeleceram mecanismos de governança para antever possíveis danos, como sugere Aguilera et al. (2015): sistema legal, controle corporativo, auditores externos, stakeholder ativista, mídia que, coaduna com o entendimento de Soutello (2001) no sentido da necessidade de meios de preservação ambiental.

Ações para preservar a integridade das hidrelétricas foi observado por Weber (2004) que desde 1960, que os vertedouros usados para a passagem de fluxo que excede a capacidade do reservatório e força a estrutura para proteção contra eventos de inundação, tais fluxos resultam em níveis excessivos de gás dissolvido na água, em particular o nitrogênio, causam doenças nos peixes e põe em risco a existência desses animais, tais fatos são consequências ou impactos de pressões antrópicas no meio natural, motivados pelo crescimento econômico, população e mudança nos padrões de consumo (CÂMARA, 2011).

O projeto na Polônia de novo sistema de apoio à energia sustentável, na forma de sistema de leilões, contudo os açudes testados estão localizados em áreas protegidas dentro da rede Natura 2000, que deverá realizar impacto ambiental ou avaliação de impacto da rede Natura 2000, sujeita a custos, requisitos mais rigorosos e um procedimento complexo. Essas exigências são a essência da governança ambiental que envolvem conjuntos de iniciativas, regras, instâncias e processos que permitem a sociedade a exercer o controle social (JACOBI; SINISGALLI, 2012).

O estudo dos efeitos da regulação por barragens a fio d'água sobre teias alimentares constatou que a concentração de $\mathrm{Hg}$ (mercúrio) no sangue pode influenciar as deficiências reprodutivas e fisiológicas em várias espécies de aves e que a contaminação oriunda da barragem a fio d'água torna-se sistêmica em razão da cadeia alimentar daquele ambiente para predadores de nível trófico. Segundo Zhouri (2005) os estudos do impacto ambiental tendem a desqualificar o ambiente em que serão projetadas as barragens, fato que reforça a reificação e invisibilidade das comunidades. Na figura 3, pode-se observar a interação dos diversos recursos em conflitos devidos à construção de hidrelétricas em diversos países. 
Figura 3: Recursos em conflitos.

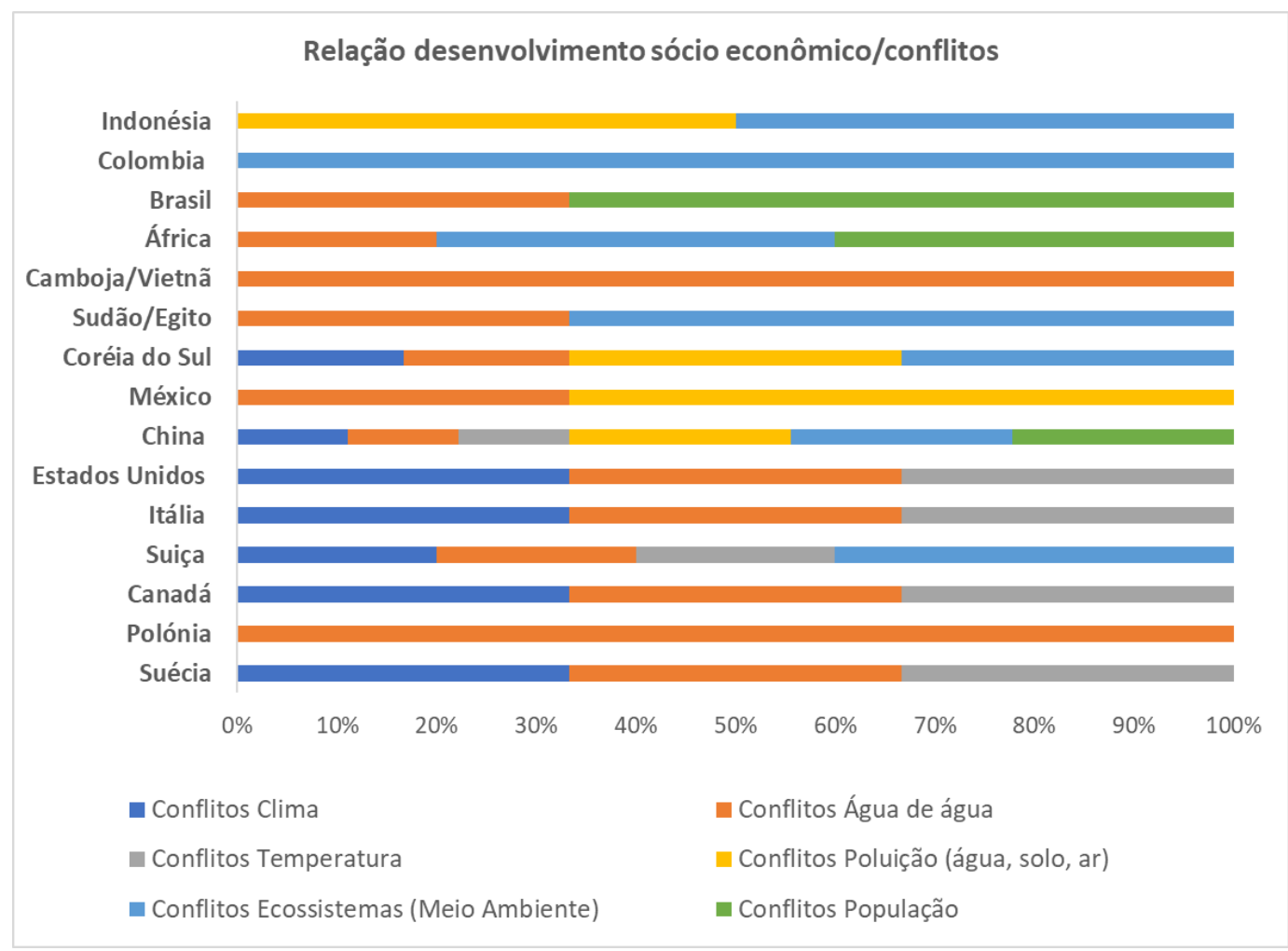

Fonte: dados da pesquisa.

Extrai-se do gráfico a separação de tipologia de conflito em relação a origem sócio econômico dos países. A exemplo dos Estados Unidos, Canadá, Itália, Suíça e Suécia os recursos em conflitos são: água, clima e temperatura, que caracteriza que as atividades das hidrelétricas são instrumentos de degradação de ambiental. Enquanto, que nos países como américa latina, Brasil e Colômbia e nos países como África e China, Indonésia, os conflitos estão mais concentrados nas áreas florestais, até porque é o local das construção das hidrelétricas que tiveram a intenção de desenvolvimento das regiões, contudo ficou claro que no estudo quanto os possíveis prejuízos humanos e da biosfera foram insipientes, em razão da perdas relevantes de espécies de animais, bem como da população que fora afetada pelo projeto, porquanto se tratar de recursos como a terra, solo, água e a população e indígenas.

Camboja, Vietnã e Polônia o conflito se dá pelo mesmo recurso, contudo em polos diferentes, isto é, Camboja e Vietnã o conflito é por inexistência de mecanismo de governança, pois a população é prejudicada quando há enchente e seca oriundas da operacionalidade das hidrelétricas. No caso da Polônia em busca de um sistema menos agressivo ao ambiente, está no impasse de construção de projetos em áreas de preservação, que terá que atender aos diversos 
mecanismos de governança ambiental daquele país. Na figura 3 considerou-se que na Colômbia apenas o conflito ecossistema em razão de que o recurso apresentado no artigo foram os répteis e, também pelos motivos culturais pelos quais a população coloca em risco de extinção esses animais, embora, o estudo foi em local de construção hidrelétricas. No México a construção de hidrelétricas na época foi por questões exploratórias, por conta do minério e interesses de empresários americanos.

No estudo notou-se que o Brasil (temporariamente) interrompeu a construção de hidrelétrica em terras indígenas, a temporalidade não dá substância para alegar que a suspensão seja um mecanismo de governança ambiental em prol a população indígena. A criação de norma estabelecendo critérios internacionais para a regulação de construção de hidrelétricas na África, também, não se pode confirmar que seja mecanismo de governança, porquanto não se sabe como será a compliance naquele país. Embora tenha observado na Polônia maior rigor nas normas para a implantação de sistema energético naquele país, o artigo não deixou claro se estão institucionalizados os princípios da governança para que os diversos atores atuem de forma conjunta para se produzir resultados eficazes para problemas comuns (GONÇALVES, 2006; QUEIROS; MOTTA VEIGA, 2012).

Por fim, em resposta ao objetivo do artigo verificou-se que alguns países, como o Brasil, Indonésia, Polônia e África utilizam da legislação como mecanismos de governança, contudo a existência da norma não é evidência de que são cumpridas pelos diversos steakholders e que de fato haja a tão almejada governança ambiental.

\section{CONCLUSÃO}

Como relação ao objetivo de identificar quais os mecanismos de governança ambiental presentes nas construções de usinas hidrelétricas, pode-se dizer que o mecanismo mais nítido no estudo foi a instituição de leis para normatização de proteção dos recursos em conflitos nos projetos de construção de usinas hidrelétricas, contudo observou-se que apenas a presença de regramento não foi suficiente para mitigar os danos causados nos recursos em ambientes de construções de hidrelétricas.

Com a escassa presença de mecanismos de governança ambiental nos artigos estudados e a dificuldade que existe para que haja a integração dos diversos steakholders para a solução dos problemas comuns a todos é que se torna relevante este estudo, pelo fato que não se trata de apenas um país ou continente que não trata o assunto com a devida seriedade que o caso requer. Como visto, além da população afetada, animais em extinção, poluição ambiental, 
confrontos por recursos, a temperatura, o clima e a água são recursos que atingem a todos de forma global.

Dentre as limitações encontradas no desenvolver do trabalho está a limitação de artigos por países estudos, o que dificulta a conclusão generalizada de que o país não existe de forma efetiva a governança ambiental. $O$ período de abrangência da pesquisa, porquanto houve artigo com 3 dias de pesquisa e outros com mais de 30 anos. Diante das limitações, sugere-se novos estudos com o objetivo de ampliar os estudos de construções de hidrelétricas em cada país, para confirmar a conclusão deste estudo. 


\section{REFERÊNCIAS}

AGUILERA, R. V. et al. Connecting the Dots: Bringing External Corporate Governance into the Corporate Governance Puzzle. The Academy of Management Annals, v. 9, n. 1, p. 483457, 2015. DOI: 10.1080/19416520.2015.1024503.

BRASIL. Ministério do Meio Ambiente. Governança ambiental. Brasília: MMA, [2020]. Disponível em: https://antigo.mma.gov.br/governanca-ambiental.html. Acesso em: 2 fev. 2021.

BRIGNOLI, M. L.; ESPA, P.; BATALLA, R. J. Sediment transport below a small alpine reservoir desilted by controlled flushing: field assessment and one-dimensional numerical simulation. Journal of Soils and Sediments, v. 17, p. 2187-2201, 2017.

CÂMARA, J. B. D. Governabilidade, governança ambiental e estado do meio ambiente no Distrito Federal. 2011. Tese (Doutorado em Desenvolvimento Sustentável) Universidade de Brasília, Brasília, 2011.

CHEEK, M. et al. A synoptic revision of inversodicraea (Podostemaceae). Blumea, v. 62, p. 125-156, 2017. DOI: 10.3767/blumea.2017.62.02.07. Available at:

https://pdfs.semanticscholar.org/e144/74235a66677d20f8271a73f1fff9365a6b15.pdf. Access in: 23 jan. 2021.

DA COSTA, M. C. A. et al. Licitações sustentáveis: aplicabilidade do decreto estadual $\mathrm{n}^{\circ}$ 21.264/2016 nas licitações públicas no estado de Rondônia. Brazilian Journal of

Development, v. 7, n. 1, p. 9163-9190, jan. 2021. DOI:10.34117/bjdv7n1-621.

DANG, T. D. et al. Future hidrological alterations in the Mekong Delta under the impacto f water resources development, land subsidence na sea level rise. Journal of Hydrology:

Regional Studies, v. 15, p. 119-133, Feb. 2018. DOI:

https://doi.org/10.1016/j.ejrh.2017.12.002. Available at:

https://www.sciencedirect.com/science/article/pii/S2214581817302021. Access in: 23 jan. 2021.

GOMIDES, J. E.; SILVA, A. C. O surgimento da expressão "governance", governança e governança ambiental: Um resgate teórico. Revista de Ciências Gerenciais, v. 13, n. 18, p. 177-194, 2009. DOI: https://doi.org/10.17921/1415-6571.2009v13n18p177-194. Disponível em: https://revista.pgsskroton.com/index.php/rcger/article/view/2618. Acesso em: 23 jan. 2021.

GONÇALVES, A. O conceito de governança. In: CONGRESSO NACIONAL DO CONPEDI/UEA, 15. 2006, Manaus. Anais [...]. Manaus: CONPEDI/UEA, 2006.

HILL, JR Jonathan. Circuits of State: Water, Electricity, and Power in Chihuahua. Radical History Review, v. 2017 n. 127, p. 13-38, 2017. DOI: https://doi.org/10.1215/016365453690846.

HIRSCH, P. E. et al. Effects of water level regulation in alpine hydropower reservoirs: an ecosystem perspective with a special emphasis on fish. Hydrobiologia, v. 794, p. 287-301, 2017. DOI: $10.1007 / \mathrm{s} 10750-017-3105-7$. 
HUA, L. et al. The complete mitochondrial genome of Schizopygopsis chengi baoxingensis (Teleostei, Cyprinidae, Schizopygopsis). Mitochondrial DNA A DNA Mapp Seq Anal., v. 27, n. 3, p. 2062-4, 2016. DOI: 10.3109/19401736.2014.982557.

IMAN, T.; COCHRANE, T. A.; ARIAS, M. E. Effect of Proposed Large Dams on Water Flows and Hydropower Production in the Sekong, Sesan and Srepok Rivers of the Mekong Basin. River Research and applications, v. 32, n. 19, p. 2095-2108, 2016.

JACOBI, P. R.; SINISGALLI, P. A. A. Governança Ambiental e economia verde. Associação Brasileira de Saúde Coletiva (Online), v. 17, n. 6, 2012. Disponível em:

https://scielosp.org/article/csc/2012.v17n6/1469-1478/. Acesso em: 22 fev. 2021.

JIN, H. et al. Enhanced greenhouse gas emission fromexposed sediments along a hydroelectric reservoir during an extreme drought event. Environmental Research Letters, v. 11, n. 12, 2016. DOI: http://dx.doi.org/10.1088/1748-9326/11/12/124003. Available from: https://iopscience.iop.org/article/10.1088/1748-9326/11/12/124003/pdf. Access in: 23 fev. 2021.

JONES, B. A. et al. In search of an inclusive approach: Measuring non-market values for the effects of complex dam, hydroelectric and river system operations. Energy Economics, v. 69, p. 225-236, 2028. Available from: https://www.scopus.com/inward/record.uri?eid=2-s2.085040769198\&. Access in: 23 fev. 2021.

JUNK, P.; RENK, A. A. Vítimas do desenvolvimento: enfrentando dogmas e confirmando heresias. Revista Direito Ambiental e Sociedade, v. 9, n. 1, p. 263-297, jan./abr. 2019. Disponível em:

http://www.ucs.br/etc/revistas/index.php/direitoambiental/article/view/7516/3874. Acesso em: 24 fev. 2021.

KONDOLF, G. M. et al. Changing Sediment Budget of the Mekong: Cumulative Threats and Management Strategies for a Large River Basin. Science of The Total Environment, v. 625, n. 1, p. 114-134, 2018. DOI: https://doi.org/10.1016/j.scitotenv.2017.11.361.

KOWALCZYK-JUŚKO, A. et al. Evaluation of the possibilities of using water-damming devices on the Tysmienica River to build small hydropower plants. Journal of Water and Land Development, n. 35, p. 113-119, 2017. DOI: 10.1515/jwld-2017-0074. Available from: http://archive.sciendo.com/JWLD/jwld.2017.35.issue-1/jwld-2017-0074/jwld-2017-0074.pdf. Access in: 12 fev. 2021.

LUTINSKI, J. A. et al. Richness and structure of ant assemblies (Hymenoptera: Fornmicidae) in Atlantic forest in Southern Brazil. An. Acad. Bras. Ciênc., v. 89, n. 4, Oct./Dec. 2017 Epub Dec 11, 2017. DOI: 10.1590/0001-3765201720160892. Available at:https://www.scielo.br/pdf/aabc/v89n4/0001-3765-aabc-201720160892.pdf. Access in: 22 jan. 2021.

MAHLAKENG, M. K. China and the Nile River Basin: The Changing Hydropolitical Status Quo. Insight on Africa, v. 10, n. 1, 2018. DOI: 10.1177/0975087817741043.

MELLO, B. B. Cumulative environmental impacts and extinction risk of Brazilian carnivores. Oecologia Australis, v. 21, n. 3, 2017. Available from: https://www.scopus.com/inward/record.uri?eid=2-s2.0-85034109620\&. Access in: 23 fev. 2021. 
MOURA, A. M. M. Governança das Políticas Ambientais no Brasil: desafios à construção de um sistema integrado de avaliação. Rio de Janeiro: IPEA, 2013.

http://repositorio.ipea.gov.br/bitstream/11058/2533/1/TD_1904.pdf.

MOURA, A. S.; BEZERRA, M. C. O papel da governança na promoção da sustentabilidade das políticas públicas no Brasil. Revista dos Mestrados Profissionais, v. 3, n. 2, 2014.

Disponível em: https://periodicos.ufpe.br/revistas/RMP/article/view/722/538. Acesso em: 22 jan. 2021.

NORRIS, D.; MICHALSKI, F.; GIBBS, J. P. Beyond harm's reach? Submersion of river turtle nesting areas and implications for restoration actions after Amazon hydropower development. PeerJ, v. 8, n. ;6, e4228, 2018. DOI: 10.7717/peerj.4228. eCollection 2018. Available from: https://www.scopus.com/inward/record.uri?eid=2-s2.0-85040103319\&. Access in: 22 jan. 2021.

NYQVIST, D. et al. Upstream and downstream passage of migrating adult Atlantic salmon: Remedial measures improve passage performance at a hydropower dam. Ecological Engineering, v. 192, p . 331-343, 2017. DOI: https://doi.org/10.1016/j.ecoleng.2017.02.055.

OLIVEIRA, R.; ZHOURI A. Paisagens Industriais e Desterritorialização de Populações Locais: conflitos socioambientais em projetos hidrelétricos. Rio de Janeiro: IPPUR/UFRJ e Fórum da Ciência, 2005. Disponível em:

http://socialsciences.scielo.org/scielo.php?script=sci_arttext\&pid=S151844712006000100001\&lng=pt.

PERCEQUILLO, A. R. et al. How many species of mammals are there in Brazil? New records of rare rodents (Roden,tia: Cricetidae: Sigmodontinae) from Amazonia raise the current known diversity. PeerJ, v. 15, n. 5, e4071, 2017. DOI:

10.7717/peerj.4071. eCollection. Available from: https://peerj.com/articles/4071/. Access in: 22 fev. 2021.

RESTREPO, A. et al. Amphibians and reptiles from two localities in the northern Andes of Colombia. Check List, v. 13, n. 4, p. 203-237.

RUBI, S. P. et al. Increased sediment load during a large-scale dam removal changes nearshore subtidal communities. Plos One, v. 12, n. 12, p. e0187742, 2017. DOI. https://doi.org/10.1371/journal.pone.0187742.

SHEN, Y. J. et al. Trends and variability in streamflow and snowmelt runoff timing in the southern Tianshan Mountains. Journal of Hydrology, v. 557, p. 173-181, 2018,. Disponível em: DOI. https://doi.org/10.1016/j.jhydrol.2017.12.035.

SOUTELlO, L. E. A. Governança e Cidadania Empresarial. Revista de Administração de Empresa, v. 41, n. 4, p. 78-86, 2001. Disponível em:

https://www.scielo.br/pdf/rae/v41n4/v41n4a09.pdf. Acesso em: 22 fev. 2021.

STUTENBECKER, L. et al. Reduced sediment supply in a fast eroding landscape? A multiproxy sediment budget of the upper Rhône basin, Central Alps. Sedimentary Geology, v. 375, p. 105-119, 2018. DOI: https://doi.org/10.1016/j.sedgeo.2017.12.013. 
TEIXEIRA, M. G. A saga de Payaré Akrãtikatêjê frente ao Estado brasileiro no contexto da construção da hidrelétrica de Tucuruí. Bol. Mus. Para. Emílio Goeldi. Ciênc. hum. [online], v.12, n. 3, p. 953-965, 2017. DOI: http://dx.doi. org/10.1590/1981.81222017000300016.

TUKIC, N.; BURGESS, M. China's role in Africa's water sector: Mapping the terrain. Waterlines, v. 35, n. 1, p. 18-36, 2016. Available from:

https://www.scopus.com/inward/record.uri?eid=2-s2.0-85014470028\&. Access in: 23 jan. 2021.

TURGEON K. et al. Do novel ecosystems follow predictable trajectories? Testing the trophic surge hypothesis in reservoirs using fish. Ecosphere, v. 7. n. 12, e01617, Dec 2016. Available from: https://www.scopus.com/inward/record.uri?eid=2-s2.0-

85007366126\&doi=10.1002\%2fecs2.1617\&partnerID=40\&md5=d5c79ab8a54e0209db277a5 7d64d9302. Access in: 23 jan. 2021.

TURNER, Sean W. D.; NG, Jia Yia; GALELI, Stefano. Examining global electricity supply vulnerability to climate change using a high-fidelity hydropower dam model. Science of The Total Environment, v. 590-591, p. 663-675, 2017. DOI:

https://doi.org/10.1016/j.scitotenv.2017.03.022.

WANG, Xu Xi. et al. Impact of Hydropower Dam Development on River Ecosystems: Ecopath Model Application on the Red River in China as an Example. Pol. J. Environ. Stud., v. 26, n. 6, p. 2811-2821, 2017. DOI: 10.15244/PJOES/73805.

WEBER, L. et al. Modeling total dissolved gas production and transport downstream of spillways: Three-dimensional development and applications. International Journal of River Basin Management, v. 2, n. 3, 2004. Available from:

https://www.scopus.com/inward/record.uri?eid=2-s2.0-85009580613\&. Access in: 23 jan. 2021.

WITHANINGSIH, S. et al. Nest existences and population of pangolin (Manis javanica desmarest, 1822 at the designated area of cisokan hydropower, West Java, Indonesia.

Biodiversitas Journal of Biological Diversity, v. 19, n. 1, 2018. Available from:

https://www.scopus.com/inward/record.uri?eid=2-s2.0-

$85039700829 \&$ doi $=10.13057 \% 2$ fbiodiv\%2fd190122\&partnerID=40\&md5=b53885570082a6 3be03e6677d2aae69a. Access in: 23 jan. 2021.

YANG, K. et al. Mass marking of juvenile Schizothorax wangchiachii (Fang) with alizarin red $\mathrm{S}$ and evaluation of stock enhancement in the Jinping area of the Yalong River. PeerJ, v. 6, n. 5, e4142, 2017. DOI: 10.7717/peerj.4142. eCollection 2017.

ZHANG, M. et al. Effects of the seasonal flooding on riparian soil seed bank in the Three Gorges Reservoir Region: a case study in Shamu River. SpringerPlus, v. 5, n. 492, 2016. DOI: 10.1186/s40064-016-2121-9. Available from:

https://springerplus.springeropen.com/track/pdf/10.1186/s40064-016-2121-9.pdf. Access in: 23 jan. 2021.

ZHOU, Y. B. et al. The Three Gorge Dam: Does it accelerate or delay the progress towards eliminating transmission of schistosomiasis in China? Infectious Diseases of Poverty, v. 5, n. 1, 2016. DOI 10.1186/s40249-016-0156-3. Available from: 
https://idpjournal.biomedcentral.com/articles/10.1186/s40249-016-0156-3. Access in: 23 jan. 2021.

ZHOURI, A. Justiça Ambiental, diversidade cultural e accountability: desafios para a governança ambiental. Rev. Bras. Ci. Soc., v. 23, n. 68, p. 97-194, 2008. DOI: https://doi.org/10.1590/S0102-69092008000300007. Disponível em:

http://www.scielo.br/pdf/rbcsoc/v23n68/v23n68a07.pdf. Acesso em: 23 jan. 2021. 